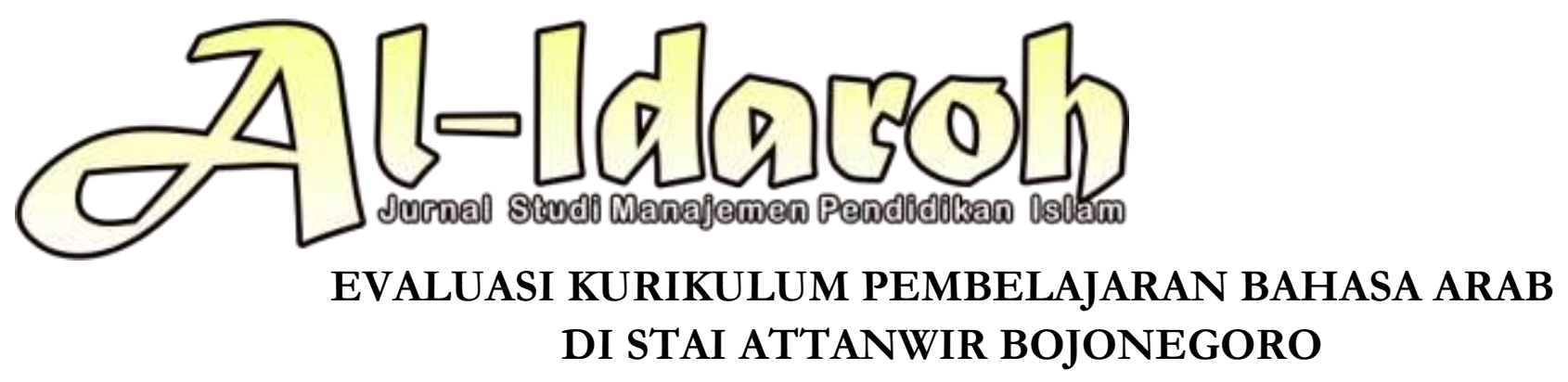

Khoirul Faizin

UIN Sunan Ampel Surabaya

Email:kfaizin6@gmail.com

\begin{abstract}
Abstrak: Language learning is the most unique part of learning, especially foreign languages as learning and in this language is Arabic. The curriculum in a learning is very influential on the level of success of students. This study examines Arabic in terms of curriculum, because researchers consider this very important for the continuity of learning foreign languages, especially Arabic so that learning can be carried out optimally and optimally. In this case the researchers conducted research at one of the tertiary institutions in Bojonegoro namely STAI Attanwir. The researcher found that there were several elements in the language learning curriculum that had to be improved, among others, from the learning media and textbooks, as well as the learning system that caused students to not be able to receive lessons to the maximum. This happened because of the different backgrounds of Arabic learning students so that Arabic learning materials could only be understood by some students.
\end{abstract}

Keywords: Evaluation, Curriculum, Arabic Learning

\title{
Pendahuluan
}

Unsur-unsur dalam kurikulum terbentuk dari beberapa komponen yaitu tujuan, isi kurikulum, metode atau strategi dan evaluasi. Disisi lain kurikulum memiliki makna yang lebih luas antar Negara atau institusi penyelenggara kurikulum. Hal tersebut lumrah terjadi karena sudut pandang yang berbeda dalam pendefinisiannya, kurikulum bisa dipandang sebagai suatu rencana yang di rencang oleh seseorang, disisi lain kurikulum juga dipandang sebagai suatu kejadian yang dipengaruhi oleh fakta dari rangkaian peristiwa yang telah direncanakan. Kurikulum adalah suatu perencanaan sistem dalam pembelajaran tidak pandang itu pada lembaga pendidikan formal ataupun non formal. Meskipun demikian kurikulum sering dipahami sebagai sistem perencanaan diberbagai jenjang pendidikan formal mulai dari sekolah dasar hingga pendidikan tinggi. Menurut kemendiknas No. 232/U/2000, mendefinisikan kurikulum pendidikan tinggi sebagai rencana dan pengaturan mengenai isi maupun bahan kajian dan pelajaran serta cara penyampaian dan 


\section{Evaluasi Kurikulum Pembelajaran Bahasa Arab di STAI Attanwir Bojonegoro}

penilaian yang digunakan sebagai pedoman penyelenggaraan kegiatan belajar mengajar diperguruan tunggi.

Kurikulum dapat diartikan sebagai suatu perencanaan kegiatan pembelajaran yang dirancang untuk mencapai suatu tujuan dalam pendidikan. Juga bisa diartikan sebuah program yang didokumenkan untuk satu tujuan dalam pendidikan yang dijabarkan dalam bentuk mata kuliah, silabus, rencana pembelajaran, dan sistem evaluasi keberhasilan. Namun sudut pandang yang lain menyatakan bahwa kurikulum juga berperan sebagai (1) manajemen pendidikan tinggi untuk menentukan arah pendidikannya, (2) filosofis yang akan mewarnai terbentuknya masyarakat dan iklim akademik, (3) patron atau pola pembelajaran, (4) atmosfer atau iklim yang terbentuk dari hasil interaksi manajerial PT dalam mencapai tujuan pembelajaran, (5) rujukan kualitas dari proses penjamin mutu, serta (6) ukuran keberhasilan PT dalam menghasilkan kelulusan yang bermanfaat bagi masyarakat. Dengan ukuran bahwa kurikulum tidak hanya berarti sebagai suatu dokumen saja, namun mempunyai peran yang kompleks dalam proses pendidikan. ${ }^{1}$

Paparan diatas dapat ditarik kesimpulan bahwa untuk mengetahui efektifitas suatu kurikulum adalah dengan melakukan evaluasi, kemudian dari evaluasi tersebut akan diketahui hasil pencapaian suatu kurikulum terhadap tujuan pembuatan kurikulum. Dalam kajian kali ini peneliti ingin mengkaji lebih dalam tentang kurikulum disalah satu perguruan tinggi di kabupaten Bojonegoro. Salah satu kampus baru di Bojonegoro yang memiliki keunggulan di prodi pendidikan bahasa arab. Satu hal yang menarik ketika peneliti ingin meneliti di kampus ini karena selain latar belakang pesantren kampus ini juga sangat represintatif untuk dijadikan penelitian karena dalam usianya yang baru seumur jagung kampus ini sudah membuka 5 program studi dengan bahasa arab sebagai salah satu prodi unggulannya. Satu alasan terkuat juga peneliti untuk meneliti di kampus ini adalah ingin mengetahui kurikulum dalam pembelajaran bahasa arab sehingga bisa menjadi pembelajaran bagi peneliti dan pembaca, khususnya untuk perguruan tinggi berbasis pesantren di Indonesia.

Penelitian ini menggunakan pendekatan penelitian kualitatif dengan menggunakan studi kasus sebagai jenis penelitannya. Penelitian ini juga merupakan

\footnotetext{
${ }^{1}$ Tresno Tresno Dermawan Kunaefi, dkk. Buku Panduan Pengembangan Kurikulum Berbasis Kompetensi Pendidikan Tinggi. (Jakarta: Dirjen Pendidikan Tinggi, 2008), 4-5
} 
studi multi situs tentang evaluasi kurikulum pembelajaran bahasa arab di STAI Attanwir Bojonegoro.

Penelitian ini menggunakan beberapa teknik pengumpulan data antara lain: a) Observasi, untuk melihat dan mengetahui proses pembelajaran bahasa arab di STAI Attanwir Bojonegoro, b) wawancara, untuk mengetahui informasi yang peneliti butuhkan kepada beberapa mahasiswa, dosen pengampu matakuliah dan pihak akademik perguruan tinggi, c) dokumentasi, untuk mengumpulkan data-data yang hubungannya dengan dokumen-dokumen terarsip yang berkaitan erat dengan pembelajaran bahasa arab di STAI Attanwir.

Setelah data-data yang dibutuhkan tersebut telah terkumpul kemudian peneliti melakukan pengolahan data dengan melakukan analisis secara mendalam untuk mengetahui tentang evaluasi pembelajaran bahasa arab di STAI Attanwir, dengan menggunakan teknik analisis data kualitatif model miles dan huberman yaitu reduksi data, data display, dan penarikan kesimpulan sebagai hasil dari penelitian.

Dalam penelitian ini setidaknya muncul beberapa rumusan pertanyaan antara lain: (1) Bagaimana proses pembelajaran yang berlangsung di prodi PBA STAI Attanwir?, (2) Bagaimana metode yang diterapkan oleh dosen pada mahasiswa PBA STAI Attanwir?, (3) Bagaimana pemahaman siswa PBA STAI Attanwir dalam pembelajaran dikelas?, (4) apakah acuan kurikulum dalam pembelajaran di kelas prodi PBA STAI Attanwir? Berangakat dari empat poin pertanyaan tersebut peneliti mulai mengumpulkan data-data yang dibutuhkan dan melakakukan pengolahan data yang akan dipaparkan lebih detail dibawah ini.

\section{Pembahasan}

\section{A. Evaluasi}

Evaluasi adalah suatu proses menimbang dan menilai suatu hal untuk kemudian diketahui kelayakannya. Evaluasi menjadi bagian integral yang sangat erat hubungannya dengan dunia pendidikan. Oleh karena itu evaluasi tidak dapat dipisahkan dengan pembelajaran. Untuk mengetahui hasil dari pembelajaran maka dibutuhkan evaluasi. Evaluasi sendiri diartikan sebagai proses mementukan 


\section{Evaluasi Kurikulum Pembelajaran Bahasa Arab di STAI Attanwir Bojonegoro}

nilai suatu objek. ${ }^{2}$ Secara umum dapat diartikan bahwa evaluasi adalah kegiatan pengendalian, penjaminan, dan penetapan mutu pendidikan terhadap berbagai komponen pendidikan pada setiap jalur, jenjang, dan jenis pendidikan sebagai bentuk pertanggungjawaban penyelenggaraan pendidikan. ${ }^{3}$

Paparan diatas mengandung kesimpulan bahwa evaluasi sangatlah dibutuhkan dalam pembelajaran karena keberhasilan suatu pembelajaran tidak akan dapat diketahui tanpa adanya evaluasi pembelajaran. Beberapa fungsi dari evaluasi dalam pembelajaran adalah seperti yang dikemukakan oleh Depdiknas Kemendikbud (2003:6) yang mengatakan bahwa tujuan evaluasi pembelajaran adalah untuk (a) melihat produktivitas dan efektivitas kegiatan belajar-mengajar, (b) memperbaiki dan menyempurnakan kegiatan guru, (c) memperbaiki, menyempurnakan dan mengembangkan program belajar-mengajar, (d) mengetahui kesulitan-kesulitan apa yang dihadapi oleh siswa selama kegiatan belajar dan mencarikan jalan keluarnya, dan (e) menempatkan siswa dalam situasi belajar-mengajar yang tepat sesuai dengan kemampuannya. Secara garis besar evaluasi adalah point terpenting dalam banyak hal termasuk pendidikan. Karena dengan evaluasi bisa diketahui efektifitas suatu pembelajaran dalam pendidikan yang hasil akhirnya akan menjadikan satu pembelajaran menjadi optimal ketika diketahui hasil dari evaluasi tersebut.

\section{B. Kurikulum}

Secara etimologi kurikulum berasal dari bahasa Latin yaitu "a little racecourse" (suatu jarak yang harus ditempuh dalam pertandingan oleh raga), yang kemudian dialihkan ke dalam pengertian pendidikan menjadi "circle of intructurtio" yaitu suatu lingkungan pengajaran, di mana guru dan murid terlibat di dalamnya. ${ }^{4}$ Sedangkan secara terminologi kurikulum disebut sebagai suatu program pendidikan yang direncanakan dan dilaksanakan untuk mencapai sejumlah tujuan pendidikan tertentu. ${ }^{5}$ Dari pengertian diatas dapat disimpulkan

\footnotetext{
${ }^{2}$ Nana Sudjana, Penilaian Hasil Proses Belajar Mengajar, (Bandung: PT Remaja Rosdakarya 1991), 3

${ }^{3}$ Depdiknas RI, Standar Nasional Pendidikan (PP RI No. 19 Tahun 2005), (Jakarta: Sinar Grafika, 2006), 4

${ }^{4}$ M.Arifin, Filsafat Pendidikan Islam, (Jakarta: Bumi Aksara,1996), 85

${ }^{5}$ Zakiah daradjat,dkk, Ilmu Pendidikan Islam, (Jakarta: Bumi Aksara,2006),122
} 


\section{Khoirul Faizin}

bahwa kurikulum adalah sebuah proses perencanaan dalam pembelajaran untuk mencapai tujuan dalam pembelajaran tersebut.

Negara Indonesia memiliki acuan kurikulum yang disebut dengan Kerangka Kualifikasi Nasional Indonesia atau KKNI. Acuan kurikulum ini adalah suatu rujukan nasional untuk meningkatkan mutu daya saing bangsa Indonesia, sebagaiamana disebutkan dalam Perpres No.8 tahun 2012, bahwa KKNI merupakan kerangka penjenjangan kualifikasi kompetensi yang dapat menyandingkan, menyertakan dan mengintegrasikan antara bidang pendidikan dan bidang pelatihan kerja serta pengalaman kerja dalam rangka pemberian pengakuan kompetensi kerja sesuaian dengan struktur pekerjaan di beberapa sektor. ${ }^{6}$

Secara umum, dapat dikatakan bahwa penyusunan kurikulum harus berdasarkan 4 komponen yaitu: 1) tujuan, 2) isi, 3) metode atau proses belajar mengajar, dan 4) evaluasi. Setiap komponen dalam kurikulum sebenarnya saling berkaitan, bahkan masing-masing merupakan bagian integral dari kurikulum tersebut. $^{7}$ Dari beberapa komponeen tersebut dapat diketahui bahwa untuk menentukan dan menilai keberhasilan suatu pembelajaran maka harus ada evaluasi diakhir pembelajaran agar kefektifitasan kurikulum dalam pembelajaran bisa benar-benar maksimal dan efektif untuk membentuk peserta didik sesuai tujuan awal disusunnya suatu kurikulum.

\section{Evaluasi Kurikulum}

Evaluasi memiliki peranan penting terhadap keberlangsungan kurikukum untuk menentukan kebijakan kaitannya dengan pembelajaran dan pengajaran. Evaluasi terhadap kurikulum juga sebagai usaha sistematis mengumpulkan informasi mengenai suatu kurikulum untuk digunakan sebagai pertimbangan mengenai nilai dan arti dari kurikulum dalam suatu konteks tertentu, juga sebagai proses untuk mengetahui apakah tujuan pendidikan sudah tercapai atau terealisasikan. ${ }^{8}$ Oleh karena itu evaluasi kurikulum sangatlah dibutuhkan agar

\footnotetext{
${ }^{6}$ Depdiknas, Buku Pedoman Kerangka Kualifikasi Nasional Indonesia, (Jakarta: Direktorat Jendral Perguruan Tinggi, 2010), i

${ }^{7}$ Zakiah daradjat,dkk, Ilmu Pendidikan Islam, 130

${ }^{8}$ Muhammad Zaini, Pengembangan Kurikulum, (Yogyakarta : Teras, 2009), 143
} 


\section{Evaluasi Kurikulum Pembelajaran Bahasa Arab di STAI Attanwir Bojonegoro}

tujuan dari pembelajaran tetap terlaksana sesuai apa yang telah ditentukan sebagai tujuan dibentuknya kurikulum tersebut.

\section{Pembelajaran Bahasa Arab}

Bahasa adalah alat komunikasi dan penghubung dalam pergaulan manusia sehari-hari, baik antara individu dengan individu, individu dengan masyarakat, individu dengan Tuhan. ${ }^{9}$ Dalam belajar bahasa tentunya seorang guru harus bisa menjadikan pembelajaran tersebut seefisien mungkin dan efektif sehingga peserta didik akan merasa mudah dalam belajar bahasa tertutama bahasa asing. Dalam belajar bahasa asing sangat dipengaruhi oleh faktor intrinsik dan faktor ektrinsik. Faktor intrinsik adalah satu faktor yang tertanam pada diri pembelajar bahasa tentang anggapan dalam belajar bahasa asing, sedangkan faktor ektrinsik adalah faktor luar yang kaitannya dengan kurikulum, sarana, media ataupun pengajar dalam pembelajaran tersebut.

Ada beberapa faktor yang mempengaruhi tercapainya suatu keterampilan dalam berbahasa antara lain: (1) untuk mendapatkan keterampilan berbahasa yang berhasil ada peran guru dan peran siswa yang seiring. Tidak mungkin cara siswa aktif tidak terpengaruh dan dikendalikan oleh guru, (2) Metode yang berhasil adalah metode langsung dengan teknik monitoring atas kesalahan bahasa dan kosa kata, (3) keberhasilan belajar bahasa dimulai dengan belajara kosa kata dan tata bahasa, baru kemudian membaca teks dengan konteks yang menarik dan berguna, (4) Pelatihan yang digunakan setiap hari untuk komponen-komponen kebahasaan dan penugasan diberikan untuk melakukan kegiatan kebahasaan secara terpadu, (5) mengingat, juga merupakan hal yang utama dalam pembelajaran bahasa, (6) sering dilakukannya praktek berbicara dengan bahasa yang digunakan, (7) pemakaian kamus sangat diperlukan. ${ }^{10}$

Bahasa arab adalah satu bahasa asing yang banyak dipelajari oleh pembelajar bahasa. Selain karena bahasa arab adalah bahasa yang identik dengan kitab-kitab kajian tentang ilmu keagamaan bahasa arab juga memiliki keindahan dari beberapa aspek. Oleh karena itu tak heran kalu banyak yang belajar bahasa

\footnotetext{
${ }^{9}$ Tayar Yusuf dan Syaiful Anwar, Metodologi Pembelajaran Agama dan Bahasa, (Jakarta: Raja Grafindo Persada, 1997), 187

${ }^{10}$ Jos Daniael Palela, Linguistik Edukasional, (Jakarta: Erlangga, 1997), 32
} 
arab bukan hanya dari kalangan pesantren namun juga akademisi yang aktif didunia perkuliahan atupun kursusan yang khusus mengkaji bahasa arab. Persebaran bahasa arab dimulai saar agama islam mulai masuk ke Indonesia yaitu sekitar abad ke-13 M hanya saja pembelajaran bahasa arab pada saat itu hanya terfokus untuk memahami al-Qur'an dan hadis dan kitab-kitab keagamaan yang banyak menggunakan bahasa arab dalam penyebarannya.

Di era ini bahasa arab berkembang dan tak hanya terfokus untuk mempelajari kitab-kitab salaf atau ilmu keagamaan. Terbukti dengan pembelajaran bahasa arab yang dengan tujuan khusus seperti : bahasa arab untuk para jamaah haji, bahasa arab untukcalon TKI, ataupun bahasa arab komunikasi secara umum.

\section{E. Pembelajaran Bahasa Arab di STAI Attanwir Bojonegoro}

Pembelajaran bahasa arab saat ini sudah berkembang pesat bukan hanya di kawasan pondok-podok salaf namun juga di perguruan tinggi atau universitas. Terbukti dengan adanya jurusan pendidikan bahas arab di beberapa IAIN, UIN dan STAIN lebih dari itu, bahasa arab juga berkembang di perguruan tinggi swasta seperti STAI, IAI. Salah satu perkembangan bahasa arab juga terjadi di STAI Attanwir Bojonegoro. Beberapa waktu lalu peneliti melakukan kajian dan observasi terkait dengan pembelajaran bahsa arab di Sekolah Tinggi Agama Islam Attanwir di Bojonegoro tersebut. Peneliti ingin mengetahui proses pembelajaran bahasa arab yang diadakan disana. Sehingga nantinya akan menjadikan tambahan khazanah keilmuan bagi peneliti dan pembaca pada umumnya.

Setelah melakukan beberapa pengumpulan data peneliti mendapatkan hasil antara lain:

\section{Metode Pembelajaran pada kelas PBA STAI Attanwir}

Pembelajaran yang dilakukan di prodi PBA STAI Attanwir mengacu kepada visi dan misi perguruan tinggi STAI ATTANWIR yaitu : (1) menyelenggarakan pendidikan tinggi berbasis pesantren yang kurikulumnya berkesinambungan mulai dari MI sampai perguruan tinggi, (2) Menyelenggarakan pendidikan tinggi untuk menghasilkan tenaga dalam bidang pendidikan islam, sains dan teknologi yang unggul, dan berdaya saing tinggi, (3) Menumbuhkan penghayatan dan pengalaman ajaran islam, dan budaya bangsa sehingga 


\section{Evaluasi Kurikulum Pembelajaran Bahasa Arab di STAI Attanwir Bojonegoro}

menjadikan sumber kearifan dalam bertindak, (4) Memperkuat imtaq dan iptek, khususnya bagi mahasiswa, dan umumnya bagi masyarakat sekitar yang secara legal formal diakui dan dibutuhkan oleh masyarakat, lembaga, instansi, dan pemerintahan, (5) Menyelenggarakan penelitian dan pengembangan ilmu untuk menghasilkan karya akademik yang unggul dan menjadi rujukan dalam pendidikan islam, sains dan teknologi, (6) membangun masyarakat melalui penerapan pendidikan islam yang relevan bagi kesejahteraan dan kemanusiaan, (7) menjalin kerjasama dengan berbagai pihak untuk meningkatkan kualitas dan kinerja STAI Attanwir, (8) membangun organisasi yang sehat berdasarkan prinsip otonomi, akuntabilitas, dan evaluasi diri secara berkesinambungan. Dengan misi Menjadi perguruan tinggi yang menghasilkan lulusan dalam kajian keislaman berbasis pesantren di Jawa Timur Tahun 2025. Atas dasar tersebutlah berkembang menjadi visi dan misi prodi PBA di STAI Attanwi yaitu: Visi: menjadi program studi pendidikan bahasa arab yang menghasilkan lulusan berkemampuan akademik dan professional dibidang pendidikan bahasa arab berbasis pesantren di Jawa Timur tahun 2026. Sedangkan misi program studi pendidikan bahasa arab yaitu (1) menyelenggarakan pendidikan dan pengajaran materi perkuliahan yang menggabungkan kurikulum pendidikan bahasa arab dengan kurikulum pesantren, (2) menyelenggarakan perkuiahan yang mengkombinasikan teori dan praktik, (3) menyelenggarakan kegiatan pelatihan bahasa arab kepada lembaga pendidikan/sekolah, (4) menyelenggarakan program penelitian dan pengabdian kepada masyarakat dalam bidang pendidikan bahasa arab. $^{11}$

Metode pembelajaran adalah cara-cara untuk melakukan aktivitas yang tersistem dari sebuah lingkungan yang terdiri dari pendidik dan peserta didik untuk saling berinteraksi dalam melakukan suatu kegiatan sehingga proses belajar berjalan dengan baik dalam arti tujuan pengajaran tercapai. ${ }^{12}$ Syarat-syarat yang harus diperhatikan oleh seorang guru dalam penggunaan metode pembelajaran adalah sebagai berikut : (1) metode yang dipergunakan harus dapat

${ }^{11}$ Dokumen PBA stai Attanwir Bojonegoro.

${ }^{12}$ Ismail. Sukaedi, 2013. Model-model Pembelajaran Modern.( Jogjakarta: Tunas Gemilang Press), 29-30 


\section{Khoirul Faizin}

membangkitkan motif, minat, atau gairah belajar siswa, (2) metode yang digunakan dapat merangsang keinginan siswa untuk belajar lebih lanjut, (3) metode yang digunakan harus dapat memberikan kesempatan bagi siswa untuk mewujudkan hasil karya, (4) metode yang digunakan harus dapat menjamin perkembangan kegiatan kepribadian siswa, (5) metode yang digunakan harus dapat mendidik murid dalam teknik belajar sendiri dan cara memperoleh pengetahuan melalui usaha pribadi, (6) metode yang digunakan harus dapat menanamkan dan mengembangkan nilai-nilai dan sikap siswa dalam kehidupan sehari-hari. ${ }^{13}$

Hasil wawancara dengan Ka.prodi PBA STAI Attanwir bahwa di prodi ini ada 6 pengajar yang spesifikasinya adalah murni sebagai pengajar bahasa arab. Berdasarkan hasil wawancara dengan beberapa dosen di prodi PBA STAI Attanwir ditemukan bahwa metode yang digunakan dalam pembelajaran cukuplah variatif. Namun 75\% dosen lebih sering menggunakan metode ceramah dalam penyampaian materi dari pada metode langsung. Secara umum ada 3 pembagian dalam pembelajaran di program studi bahasa arab yaitu kuliah pengantar meliputi materi umum yang harus diketahui oleh mahasiswa, mata kuliah kaitannya dengan metode penyampaian pembelajaran dalam bahasa arab, dan mata kuliah bahasa arab itu sendiri.

Wawancara dengan beberapa dosen di prodi PBA STAI Attanwir bahwa media yang digunakan dalam pembelajaran adalah media proyektor namun beberapa dosen menggunakan metode langsung dengan mengajak siswa untuk aktif berbicara dan diskusi dengan rekan mahasiswa yang lain.

Dari beberapa mata kuliah yang diberikan dosen menggunakan buku ajar dirasa cocok dan sesuai dengan mata kuliah yang di ajarkan. Salah satu dosen yang bernama Abd. Hafid dalam pembelajaran mata kuliah "Tathbiq al-Nabwi" menggunakan kitab “amtsilati”. Dimaksudkan dengan kitab ini mahasiswa bisa memahami gramatikal bahasa arab dengan praktis dan mudah. Bebeda dengan ibu Jauharotun Ni'mah yang kini sedang menempuh s3 di salah satu universitas di Indonesia beliau memberi kebebasan kepada mahasiswa untuk menggunakan

${ }^{13}$ Ahmad Sabri, Strategi Belajar Mengajar Micro Teaching, (Jakarta : Quantum Teaching, 2005), $52-53$ 


\section{Evaluasi Kurikulum Pembelajaran Bahasa Arab} di STAI Attanwir Bojonegoro

rujukan dalam mata kuliah beliau yaitu "Tathbiq as Sharfi" dimaksudkan agar mahasiswa lebih memiliki pemahaman yang luas tentang shorof dan teidak terjebak oleh satu kaidah tanpa mengetahui perbandingan dengan kaidah yang lain.

Dari hasil angket yang disebar ditemukan ada 70\% mahasiswa prodi PBA STAI Attanwir yang pernah mengenyam pendidikan bahasa arab sebelumnya. Dan selebihnya 30\% adalah mahasiswa yang memang masih awam dan pemula dalam belajar bahasa arab. Sehingga ada beberapa dalam pembelajaran bahasa arab terutama kerena ada kesenjangan pengetahuan diantara mahasiswa. Sehingga memberikan kendala tersendiri bagi dosen atau pendidik dalam penyampaian materi kaitannya unsur-unsur kebahasaan dan gramatika bahasa arab.

\section{Tanggapan Mahasiswa Terhadap Proses Pembelajaran}

Pembelajaran adalah membelajarkan siswa menggunakan asas pendidikan meupun teori belajar yang merupakan penentu utama keberhasilan pendidikan. Pembelajaran merupakan proses komunikasi dua arah. Mengajar dilakukan oleh pihak guru sebagai pendidik, sedangkan belajar dilakukan oleh peserta didik. ${ }^{14}$ Pendapat lain mengatakan bahwa pembelajaran merupakan suatu kombinasi yang tersusun meliputi unsur-unsur manusiawi, material pasilitas, perlengkapan dan prosedur yang saling mempengaruhi mencapai tujuan pembelajaran. Manusia yang terlibat dalam proses pembelajaran terdiri atas siswa, guru dan tenaga lainnya, misalnya tenaga labolatorium. Materil meliputi buku-buku, papan tulis, fotografi, slide dan video tape. Fasilitas dan perlengkapan terdiri dari ruangan kelas, perlengkapan audio visual juga komputer. Prosedur meliputi jadwal, dan metose penyampaian informasi, praktek, balajar, ujian dan sebagainya. ${ }^{15}$ Pada dasarnya peserta didik adalah unsur yang sangat penting dalam pembelajaran. Dalam hal ini mahasiswa adalah bagian dari peserta didik dalam pembelajaran di prodi PBA STAI Attanwir. Oleh karena itu dirasa perlu bagi peneliti untuk mengemukakan tanggapan mahasiswa terhadap pembelajaran yang dilakukan dikelas. Dari hasil observasi dan wawancara peneliti dengan mahasiswa, peneliti mendapatkan beberapa informasi antara lain: bahwa pembelajaran yang diikuti

\footnotetext{
${ }^{14}$ Syaiful Sagala, Konsep dan Makna pembelajaran, (Bandung:Alfabexta,2005), 61

${ }^{15}$ Oemar Hamalik, Kurikulum dan Pembelajaran, (Jakarta:Bumi Aksara,2003), 61
} 
mahasiswa umumnya adalah pembealajaran yang mudah diterima dam dipahami. Ketika pertanyaan tentang pembelajaran mata kuliah yang kaitannya dengan bahasa arab peneliti utarakan maka salah satu mahasiswa PBA STAI Attanwir yang bernama Muhammad Asrori berkata "memang sih dalam pembelajaran saya mengerti dan faham dengan apa yang disampaikan oleh dosen, hanya saja beberapa dari teman kita tidak paham dengan alasan bahwa mereka tidak pernah belajar ini sebelumnya, karena latar belakang mereka adalah pendidikan formal non islami".

Wawancara dengan salah satu mahasiswa yang bernama Bayu Handoko tentang buku ajar menemukan satu kesimpulan bahwa terdapat beberpa buku ajar yang kurang relefan dipakai dalam pembelajaran bahasa arab di STAI Attanwir. Karena tingkat materi yang disampaikan terlalu berat bagi sebagian mahasiswa yang latar belakangnya tidak pernah belajar bahasa arab sebelumnya.

\section{Kesimpulan}

Penelitian ini memberikan pengertian tentang kurikulum yang dirancang di pada pembelajaran di kelas PBA di STAI Attanwir antara lain; (1) proses pembelajaran di prodi PBA STAI Attanwir menggunakan beberapa metode sesuai dengan apa topik dari mata kuliah yang di ampu oleh dosen, dalam prakteknya pendidik yang dalam hal ini adalah dosen bebas menggunakan bahan ajar dan media yang sesuai dengan materi yang ingin disampaikan, (2) metode yang penyampaian materi yang dilakukan oleh dosen adalah beragam ada yang menggunakan metode langsung, metode terjemah, metode diskusi dan sebagainya disesuaikan dengan kebutuhan dan minat peserta didik atau mahasiswa dalam pembelajaran tersebut, (3) materi yang disampaikan diterima dengan baik oleh mahasiswa hanya saja kurang pemerataan kelas dalam pembelajaran menimbulkan tumpang tindih keilmuan yang ada karena dalam satu kelas tidak semuanya pernah mempelajari bahasa arab, dan (4) acuan dalam pembuatan kurikulum adalah visi dan misi dari sekolah tinggi dan dikerucutkan menjadi visi dan misi prodi PBA STAI Attanwir dan diturunkan menjadi kurikulum yang ada. Penelitian ini diharapkan mampu memberikan kontribusi kepada pmbaca dalam mengembangkan kurikulum pembelajaran bahasa 


\section{Evaluasi Kurikulum Pembelajaran Bahasa Arab}

di STAI Attanwir Bojonegoro

arab dan juga kepada sekolah tinggi agama islam Attanwir sebagai salah satu kontribusi peneliti kepada STAI Attanwir.

\section{Daftar Rujukan}

Tresno, Dermawan Kunaefi dkk, 2008. Buku Panduan Pengembangan Kurikulum Berbasis Kompetensi Pendidikan Tinggi, Jakarta: Dirjen Pendidikan Tinggi.

Sudjana, Nana. 1991. Penilaian Hasil Proses Belajar Mengajar, Bandung: PT Remaja Rosdakarya.

Depdiknas RI. 2006. Standar Nasional Pendidikan (PP RI No. 19 Tahun 2005), Jakarta: Sinar Grafika, 2006

H. M. Arifin. 1996. Filsafat Pendidikan Islam, Jakarta: Bumi Aksara.

Zakiah daradjat, dkk. 2006. Ilmu Pendidikan Islam, Jakarta: Bumi Aksara

Depdiknas. 2010. Buku Pedoman Kerangka Kualifikasi Nasional Indonesia, Jakarta: Direktorat Jendral Perguruan Tinggi.

Yusuf, Tayar. dan Anwar, Syaiful. 1997. Metodologi Pembelajaran Agama dan Bahasa, Jakarta: Raja Grafindo Persada.

Palela, Jos Daniael. 1997. Linguistik Edukasional, Jakarta: Erlangga.

Dokumen PBA stai Attanwir Bojonegoro.

Ismail, Sukaedi. 2013. Model-model Pembelajaran Modern, Jogjakarta: Tunas Gemilang Press

Sabri, Ahmad. 2005. Strategi Belajar Mengajar Micro Teaching, Jakarta: Quantum Teaching.

Sagala, Syaiful. 2005. Konsep dan Makna pembelajaran, Bandung: Alfabexta

Hamalik, Oemar. 2003. Kurikulum dan Pembelajaran, Jakarta:Bumi Aksara.

Zaini, Muhammad. 2009. Pengembangan Kurikulum, Yogyakarta: Teras. 